\title{
Evaluation of the application of fungicides of inorganic copper compounds in apple and plum agroecosystems of the Krasnodar territory
}

\author{
Galina Yakuba *, Marina Podgornaya, Irina Mishchenko, Nadezhda Didenko, and Vasily \\ Chernov
}

Federal State Budget Scientific Institution «North Caucasian Federal Scientific Center of Horticulture, Viticulture, Wine-making», 40 Let Pobedy str., 39, 350901 Krasnodar, Russia

\begin{abstract}
In unstable environmental conditions, research on replacing pesticides with high consumption rates with modern ones with lower consumption rates, determining their effect on productivity and biometric indicators of a culture is relevant. The goal of the research was to evaluate the use of fungicides of inorganic copper compounds as the main xenobiotics in apple and plum agroecosystems in the Krasnodar Territory and development elements of energy-saving protection technologies for changing weather conditions that ensure maximum efficiency with minimal ecotoxicity. The studies were carried out in 2018-2020. In extreme weather conditions, the preparations Champ DP, WDG and Kocide 2000, WDG showed the effectiveness of apple scab control at the level of $96.8- \pm 0.6 \%$. Fungicides Cuproxat, SC and Terpen C, SC in the control of Klyasterosporioz plum - at the level of $92.2-99.0 \%$. Fungicides of the copper group had a negative effect on apple and plum plants: a decrease in the length of annual shoots and leaf area was noted. The use of Terpen $\mathrm{C}, \mathrm{SC}$, containing terpene stimuli, stimulated the growth of one-year plum shoots by $27.7 \%$ and an increase in the leaf area by $11.6 \%$, in comparison with the control. The content of copper in the fruits of apple and plum trees and in the soil under their plantations was in accordance with the requirements not exceeding hygienic standards. The results obtained can be used to develop elements of energy-saving technologies for protecting apple and plum trees in a changing climate.
\end{abstract}

\section{Introduction}

Of the fruit crops of the Krasnodar Territory, the most common and popular are apple and plum. The agroclimatic conditions of the region are favorable for the formation of highquality fruits of these species. Due to the violation of the phytosanitary stability of apple and plum agroecosystems, caused by changes in the main meteorological parameters of the climate, increased frequency of the onset of extreme weather conditions, and an increase in anthropogenic impact, protection from diseases requires the development of scienceintensive energy-saving technologies that combine high efficiency with environmental

*Corresponding author: galyayaku@gmail.com 
safety. One of the ways to achieve a stable phytosanitary situation in agrocenoses is the search for opportunities to reduce pesticide load with mechanisms of stability of biocenoses and internal relationships between their components in protection systems [1]. On the apple tree, the greatest damage is caused by scab, Venturia inaequalis (Cke.) Wint., which in the years of epiphytoties affects up to $100 \%$ of leaves and fruits on highly susceptible varieties. Both in the Russian Federation and abroad, in pathogen control programs, a special place is occupied by treatments aimed at blocking its ascospore infection, the effectiveness of which affects the success of subsequent protective measures. In the gardens of the South of Russia, as a rule, two such treatments are carried out before the apple tree blossoms with fungicides of the group of inorganic copper compounds. At the same time, the modern system of protection against scab of highly susceptible apple varieties of late ripening in the years of epiphytoties consists of 22-24 sprays, which makes the lack of contact fungicides evident in the second half of the growing season. However, the use of copper-containing fungicides on most apple varieties is limited in time - only before flowering, due to the possible phytotoxicity of copper on sensitive varieties. On the plum, fungicides of the copper group are widely used against a complex of mycoses, the most common and harmful of which is klyasterosporioz, the causative agent Stigmina carpophila (Lév.) M.B. Ellis). The pathogen affects leaves, shoots, flower buds, ovaries and fruits. The injuriousness of the disease is expressed in the oppression of trees, a reduction in their productivity, a decrease in the quality of fruits [2]. Under the conditions of the region, there is an increase in the spread of klyasterosporioz on shoots up to $40 \%$, on leaves up to $90 \%$.

As you know, copper-containing fungicides have been widely used in agriculture for more than a century to control bacterial and fungal diseases of fruit, vegetable, nut-bearing and other crops, remaining the main group of drugs in the program to overcome resistance to systemic fungicides [3]. Copper salts have an extremely small particle size, and the original formula creates an effective barrier against disease, working across direct contact with the pathogen [4]. It is known that copper perhaps have various negative impacts on the environment, including the protected plant. However, there are currently no approved alternatives to cupriferous fungicides. In Russia and abroad, the possibility of reducing the use of copper by using new compositions is being studied, but while maintaining efficiency, since otherwise the quality and quantity of the crop may be at risk. Copper-containing fungicides are popular due to their low cost and the absence of the risk of developing resistance to them in pathogens, however, when using them, a number of negative impacts on the environment arise [5].

Of the inorganic copper compounds in apple and plum protection programs, the most widely used are copper sulfate, copper oxychloride and copper hydroxide [6, 7, 8]. Analysis of literature sources showed that of these active substances, the effectiveness of preparations based on copper hydroxide against apple scab has been insufficiently studied, including in extreme weather conditions. For industrial plantations of plums, only two copper-containing fungicides have been registered, which also raises the problem of studying their effectiveness in unstable environmental conditions. The response of a plant organism to negative influences, first of all, can be determined by the appearance and condition of plants, as well as by the transformation of their biometric indicators [9]. The leaf is the main assimilating organ of the plant, in which organic substances are formed, which serve as the structural and energetic material for the entire tree [10]. Indicators of leaf surface area and plant shoot length are widely used in botanical, physiological and agronomic research.

Many scientific works have been devoted to the issue of the aftereffect of coppercontaining fungicides on perennial plantations, but the opinions of researchers differ. Some believe that these pesticides are safe, others that their prolonged use negatively affects the productivity of the plant and the quality of products. Numerous studies have shown that the annual use of copper-based fungicides led to an increase in the concentration of $\mathrm{Cu}$ in the soil 
garden agrocenoses in France, India, Australia, the USA and other countries of the world [11]. It was found that the high content of copper in the soil negatively affects the diversity of macroorganisms and microbial communities, such as earthworms, nematodes, snails, etc. [12]. According to Manivasagaperumal et al. [13], copper residues can inhibit the rate of nitrogen fixation of Rhizobium, thereby reducing soil fertility. The influence of coppercontaining treatments on the protected apple plant in the Russian Federation was studied by E. M. Drozdovskiy, E. V. Kaplunova, V. M. Smolyakova, M. E. Podgornaya. and many other researchers. It was found that in the Kuban and Black Sea horticultural zones of the Krasnodar Territory, the content of gross copper was noted in the range of 1.2 - 5.6 MAC, which led to decrease in the annual growth and the area of the leaf blade $[14,15]$. Currently, in organic farming, for most countries of the world, the use of copper-based fungicides no more than $6 \mathrm{~kg}$ of active ingredient per growing season is allowed, therefore, a decrease is not expected in the accumulation of copper in agricultural soils, especially in fruit cultivated articulation.

In connection with the above, research on replacing fungicides with high consumption rates for modern drugs with lower consumption rates and minimal ecotoxicity, selection of the optimal timing of their application, as well as a comparative analysis of their effectiveness and assessment of the impact on productivity and biometric indicators of a culture in specific conditions are relevant cultivation.

The aim of the research was to evaluate the use of fungicides of inorganic copper compounds as the main xenobiotics in apple and plum agroecosystems in the Krasnodar Territory and to develop elements of energy-saving protection technologies for changing weather conditions that ensure maximum efficiency with minimal ecotoxicity. In accordance with this goal, the following tasks were solved: assessment of the biological effectiveness of fungicides of inorganic copper compounds against scab and klyasterosporioz; determination of the effect of copper-containing preparations on the length of one-year growth, leaf area, biochemical composition of apple fruits; study of the dynamics of residual amounts of these fungicides in the soil and fruits of apple and plum trees. This article presents the results of determining the effect of fungicides of inorganic copper compounds on agrobiological indicators and the dynamics of their residual amounts.

\section{Materials and methods}

The researches were carried out in 2018-2020. The objects of research were fungicides of the copper group. On an apple tree - based on copper hydroxide: Champ DP, WDG (576 g/l) and Kocide 2000, WDG $(350 \mathrm{~g} / \mathrm{kg})$. On the plum - preparations with different active ingredients: a new innovative mix-fungicide Terpen C, SC (400 g/l copper hydroxide); Cuproxat, SC (345 $\mathrm{g} / \mathrm{l}$ of tribasic copper sulfate); Abiga-Peak, WS (400 g/l copper oxychloride). All preparations based on copper salts are contact protective fungicides that do not penetrate into plant cells, but remain on the surface in a thin layer. In contact with the treated surface, fungal spores absorb copper ions. Copper disturbance in metabolism of pathogens - the protein synthesis (causes their nonspecific denaturation), the work of cell membranes and various enzymes, and also enters into opposition with other metals through the formation of chelate compounds, which provokes metabolic disorders, leads to blocking the penetration of spores into the plant and their death [16]. The innovative mix-fungicide Terpen $\mathrm{C}, \mathrm{SC}$, in addition, contains terpenic acids, which have high adhesive properties and are immunomodulators.

The studies were carried out by methods of laboratory analyzes, setting up field experiments, comparative analysis using generally accepted and adapted methods $[17,18]$. Location of field experiments: the central subzone of the Kuban zone of the Krasnodar Territory. The experiments were carried out against a natural infectious background. The replication - three times. On an apple tree, the experiments were carried out at the stationary 
site of ZAO EPF “Tsentralnoe", Krasnodar. Champion variety, highly susceptible to scab, planted in 2010, stock M 9, planting pattern $4.5 \times 1.2 \mathrm{~m}$, tree height 2.0-2.5 m. Fungicide Champ DP, WDG was used with a consumption rate of $2.5 \mathrm{~kg} / \mathrm{ha}$, the preparation Kocide 2000 , WDG (standard) with a consumption rate of $3.0 \mathrm{~kg} / \mathrm{ha}$. Cultural treatments were carried out in the second half of the growing season (July): at the stage of development of the apple tree " $60 \%$ of the variety-typical fruit size achieved" and " $70 \%$ of the variety-typical fruit size achieved" [19]. Operating fluid consumption - at the rate of $10001 /$ ha. The biological effectiveness determined of the studied fungicides in the control of scab. The action of copper group fungicides was studied under the following weather conditions (table).

Table 1. Meteorological data for the growing seasons 2018-2020 (according to the data of the

Krasnodar Regional Center for Hydrology and Environmental Monitoring), Krasnodar

\begin{tabular}{|c|c|c|c|c|c|c|c|c|c|c|c|c|}
\hline \multirow{3}{*}{$\begin{array}{c}\text { Indi } \\
\text { cato } \\
\text { rs }\end{array}$} & \multicolumn{12}{|c|}{ Months and decades } \\
\hline & \multicolumn{3}{|c|}{ April } & \multicolumn{3}{|c|}{ May } & \multicolumn{3}{|c|}{ June } & \multicolumn{3}{|c|}{ July } \\
\hline & I & II & III & I & II & III & I & II & III & $\mathbf{I}$ & II & III \\
\hline \multicolumn{13}{|c|}{2018} \\
\hline 1 & 12,4 & 13,3 & 15,7 & 19,1 & 17,8 & 21,1 & 20,6 & 23,7 & 27,0 & 26,4 & 25,9 & 26,2 \\
\hline 2 & 11,0 & 11,7 & 12,6 & 14,7 & 16,9 & 18,2 & 19,8 & 20,9 & 21,6 & 22,9 & 23,4 & 23,9 \\
\hline 3 & 8,8 & 15,0 & 3,3 & 25,5 & 15,5 & 4,7 & 0 & 3,3 & 7,3 & 0 & 110,4 & 15,1 \\
\hline 4 & 11,0 & 21,1 & 22,0 & 19,0 & 11,6 & 29,4 & 26,8 & 17,4 & 38,4 & 25,0 & 17,0 & 17,0 \\
\hline \multicolumn{13}{|c|}{2019} \\
\hline 1 & 10,7 & 10,8 & 14,1 & 16,7 & 19,4 & 21,0 & 24,2 & 26,2 & 25,4 & 24,1 & 21,0 & 23,8 \\
\hline 2 & 10,4 & 9,9 & 15,6 & 14,7 & 16,9 & 18,2 & 19,8 & 20,9 & 21,6 & 22,9 & 23,4 & 23,9 \\
\hline 3 & 5,0 & 39,1 & 0,1 & 16,5 & 9,9 & 26,9 & 9,8 & 2,3 & 22,6 & 1,7 & 61,4 & 67,2 \\
\hline 4 & 11,1 & 21,0 & 22,0 & 19,0 & 18,0 & 28,9 & 20,0 & 16,4 & 38,3 & 28,3 & 17,0 & 17,0 \\
\hline \multicolumn{13}{|c|}{2020} \\
\hline 1 & 8,7 & 10,8 & 11,7 & 15,5 & 17,5 & 16,4 & 21,0 & 23.2 & 24,4 & 27,1 & 24,5 & 24,7 \\
\hline 2 & 11,0 & 11,6 & 12,6 & 14,7 & 16,9 & 18,2 & 19,8 & 20,9 & 21,6 & 22,9 & 23,4 & 23,9 \\
\hline 3 & 0,0 & 3,8 & 0,5 & 28,3 & 0,0 & 61,6 & 17,5 & 20,1 & 1,0 & 18,0 & 27,7 & 60,6 \\
\hline 4 & 25,5 & 21,1 & 25,0 & 19,0 & 25,0 & 29,0 & 0,0 & 17,0 & 33,3 & 26,9 & 17,0 & 16,9 \\
\hline
\end{tabular}

Legend:

1 - Temperature of the current year, ten-day average, ${ }^{\circ} \mathrm{C}$;

2 - Average long-term temperature for a decade, ${ }^{\circ} \mathrm{C}$;

3 - Precipitation of the current year for a decade, $\mathrm{mm}$;

4 - Average long-term precipitation over a decade, $\mathrm{mm}$.

Annually - with an abnormal amount of precipitation; in 2018 - in conditions of an increased, in comparison with perennial indicators, temperature regime, in 2019 - in conditions of a reduced temperature regime, in 2020 - at a temperature at the normal level. On the plum, the experiments were carried out at the vegetation station NCFSCHVW. Variety Kabardinskaya early, highly susceptible to klyasterosporioz, 2001 bedding. Planting pattern $3 \times 2 \mathrm{~m}$. The height of the trees is 2.5-3.0 m. Fungicide Abiga-Peak, WS was used with consumption rates of 9.6 (before flowering) and $4.81 /$ ha (after flowering), Cuproxat, SC - with a consumption rate of $5.0 \mathrm{~kg} / \mathrm{ha}$, Terpen C, SC - with a consumption rate of $2.5 \mathrm{l} / \mathrm{ha}$. The first two treatments with copper fungicides were carried out at the stage of plum development "green cone" and "white bud", the third and four-fold treatments - immediately after flowering with a 10-day interval: at the stage "the ovary increases" and "the second fruit abscission (abscission of reddish fruits)". Operating fluid consumption - at the rate of 1000 1/ha. The biological effectiveness determined of the studied fungicides in the control of klyasterosporioz. The action of fungicides of copper-containing preparations proceeded under the following weather conditions in April-May. In 2018, when the amount of precipitation is above normal and under conditions of a low temperature regime before plum flowering and at an elevated temperature after flowering. In 2019, with a significant shortage of precipitation and elevated temperatures before and after plum flowering. In 2020, also 
under conditions of a significant shortage of precipitation and against the background of abnormally high temperatures before plum flowering and slightly above the norm after flowering. The increment length and leaf surface area of apple and plum trees were determined in the second half of the growing season at the end of shoot growth (late July early August) by direct measurement of shoots from each model tree. Leaf surface area was calculated using overlay chart [20]. To determine the content of gross forms of copper in garden agrocenoses, soil samples and fruits of apple and plum were taken on the 0th day (3 hours after the last treatment), then on the 5th, 10th, 15th and 20th days. The copper content in fruits was determined according to GOST 26931-86 [21]; in soil according to M-MVI-802008 , the method is based on measuring the radiation intensity of the atoms of the elements being determined, which occurs when the solution of the analyzed sample is sprayed into argon plasma, inductively excited by a radio frequency electromagnetic field [22].

\section{Results and discussion}

On the apple tree, during the years of research on the experimental plot, a weak development of scab was noted. In the second half of the growing season during the period of application of copper-containing fungicides, the intensity of disease development varied in the range of $9.8-14.6 \%$ in 2018 , in the range of $5.2-7.1 \%$ in 2019 and in the range of $11.7-16,5 \%$ in 2020 . Determination of the biological effectiveness of copper-containing fungicides showed that they ensured suppression of conidial scab infection for 8 -14 days at the level of $96.8 \pm 0.6 \%$. The new fungicide Champ DP, WDG didn't yield to the standard version in protection against disease. Thus, a stable and highly effective action of modern fungicides of the copper group against apple scab in extreme weather conditions has been established. On the plum, according to three-year data, after double application before flowering of Cuproxat, SC and Terpen C, SC, complete blocking of the disease was ensured, after the application of AbigaPeak, WS - by $98.5 \pm 0.4 \%$, with the intensity of the development of the disease in the control 0.05-0.6\%. After plum flowering, the biological effectiveness of the preparations Cuproxat, SC and Terpen C, SC was at the level of $92.2 \pm 0.3 \%$, the drug Abiga-Peak, WS - at the level of $85.5 \pm 0.8 \%$, with the intensity of the development of the disease in the control from 10.2 to $27.0 \%$. Thus, during the period of increased temperature conditions, the biological efficiency of Abiga-Peak, WS with a 10-day interval between treatments was lower than that of the other two fungicides.

Determination of the leaf area of apple and plum in the variants of the experiment showed the following (Figure 1). On an apple tree at an elevated temperature regime $(2018,2020)$, the use of fungicides with the active ingredient copper hydroxide can lead to a decrease in the leaf area. At a lowered temperature regime (2019), the differences with the control of both variants were insignificant. On the plum, after four times treatment with Abiga-Peak, WS and Cuproxat, SC, the values of the leaf area indicators were lower in comparison with the control. In the variant of using Terpen C, SC, this index, on the contrary, was higher than in the control. 


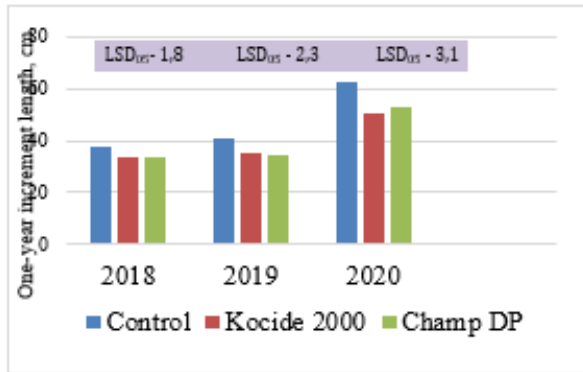

Apple

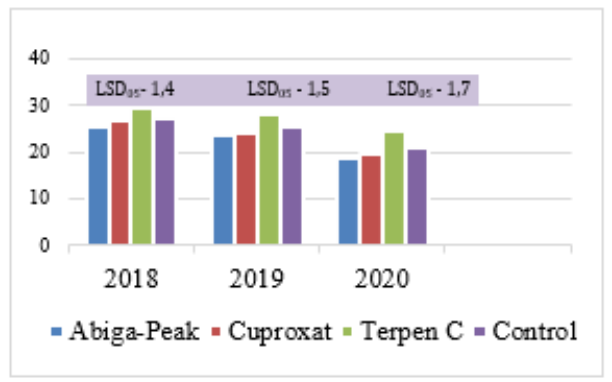

Plum

Fig. 1. The area of the leaf blade of an apple tree of the Champion variety and of a plum of the Kabardinskaya early variety against the background of the use of fungicides of the chemical group of inorganic compounds of copper salts in 2018-2020, cm2 (*LSD - Least Significant Difference)

It was found that the use of copper hydroxide had an effect on the length of the one-year growth of the Champion apple tree with a planting scheme of $4.5 \times 1.2 \mathrm{~m}$ : the growth, in comparison with the control, decreased (Figure 2). The differences between the variants of the use of Champ DP, WDG and Kocide 2000, WDG were insignificant. On average, over three years, the decrease in the length of the one-year growth of the apple tree, in comparison with the control, was $18.6-20.9 \%$. No influence on this indicator of the temperature regime was revealed. On the plum, treatment with fungicides Abiga-Peak, WS and Cuproxat, SC caused, in comparison with the control, also a decrease in the length of the one-year growth of the Kabardinskaya early variety with a planting scheme of $3 \times 2 \mathrm{~m}$. In the variant of using Terpen $\mathrm{C}, \mathrm{SC}$, on the contrary, an increase in the increase was noted.

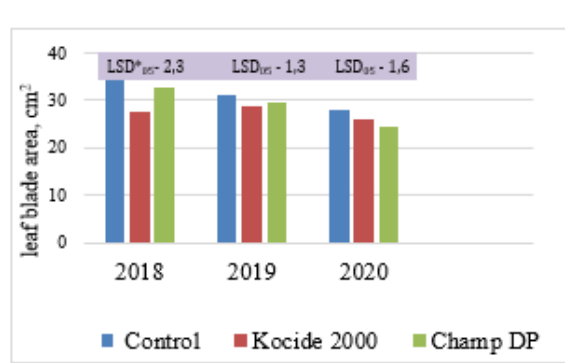

Apple

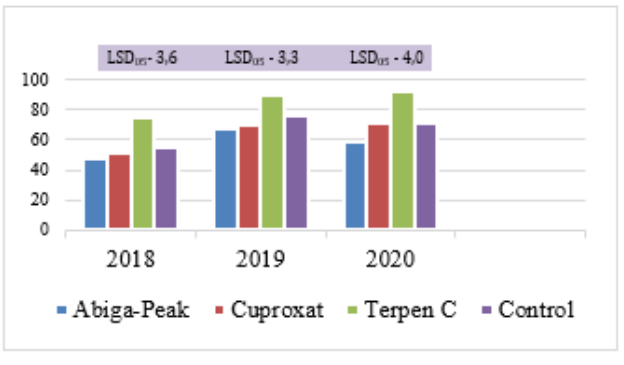

Plum

Fig. 2. The length of the one-year growth of the Champion apple-tree and the Kabardinskaya early plum variety against the background of the use of fungicides of the chemical group of inorganic compounds of copper salts in 2018-2020, cm

In general, the use of copper-containing fungicides Abiga-Peak, WS and Cuproxat, SC on the plum had a negative effect on shoot growth and leaf size, and terpene acids contained in the fungicide Terpen C, SC stimulated the growth of annual shoots and caused an increase in the area of the leaf plate. It was found that the content of copper in the fruits of apple, plum and in the soil under their plantations was in concentrations not exceeding the hygienic standards established in the Russian Federation. The maximum indices of the content of gross forms of copper (82.0-72.0 mg / kg) were noted in the soil of an apple-tree garden in the variants Kocide 2000, WDG and Champ DP, WDG within 20 days after application, the maximum permissible concentration (MPC) of gross forms of copper for leached chernozems is $132 \mathrm{mg} / \mathrm{kg}$. In the soil of the control variant, the concentration of copper varied within $48.0-52.0 \mathrm{mg} / \mathrm{kg}$ during the entire growing season. In the pilot area of the plum, the copper content was in the range of $69.0-56.0 \mathrm{mg} / \mathrm{kg}$ in the treatments of Abiga-Peak, WS and 
Cuproxat, SC, which is 1.4-1.2 times higher than the indicators obtained in the treatment of Terpen $\mathrm{C}, \mathrm{SC}$ and 2.5-2.2 times the control variant.

In the fruits of apple and plum in all treated variants of the experiment, higher indicators (not exceeding the maximum allowable levels) were noted within 15 days after the treatments, the content on the 20th day and during the harvest period was identical (Figure $3)$.

Thus, it was found that the use of copper-containing preparations does not lead to contamination of garden agrocenoses with residual amounts of gross forms of copper. The use of the preparation Terpen $\mathrm{C}, \mathrm{SC}$, in addition, allows to reduce the pesticide load on the soil due to the lower rate of copper application.
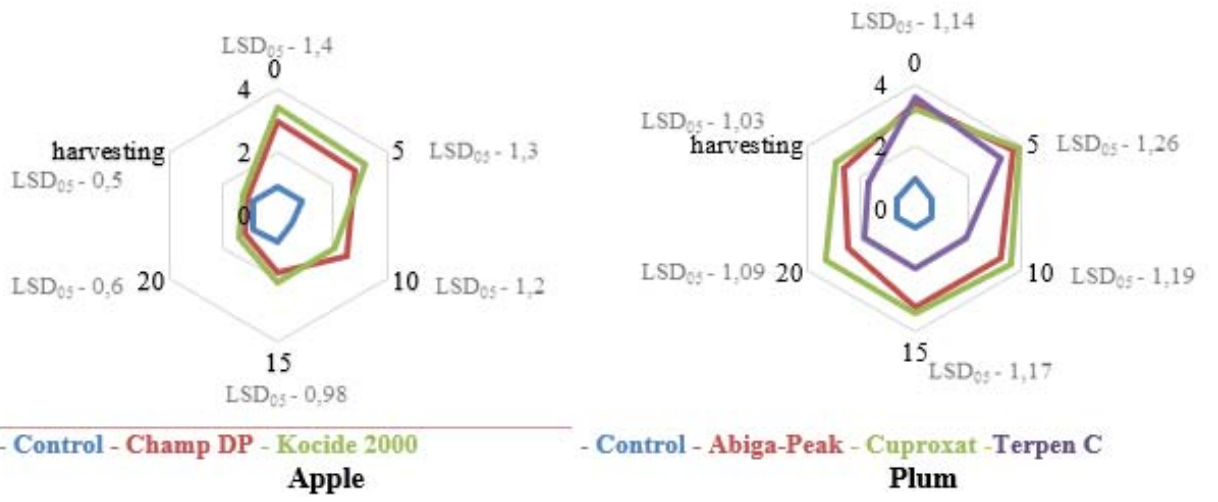

Fig. 3. Content of gross forms of copper in apple and plum fruits, $\mathrm{mg} / \mathrm{kg}, 2018-2020$.

\section{Conclusions}

New experimental data have been obtained on the action of modern fungicides of the copper group with the active ingredient copper hydroxide in protecting apple trees from scab in extreme weather conditions: when the temperature exceeds the average annual temperature by $1.1-3.5^{\circ} \mathrm{C}$, or, on the contrary, at an average temperature of $2,4^{\circ} \mathrm{C}$ below normal; in the absence of precipitation or falling out $163-395 \%$ of the norm. The preparations Champ DP, WDG and Kocide 2000, WDG have shown high efficiency in scab control. In the control of plum klyasterosporioz, preparations with active ingredients copper hydroxide and tribasic copper sulfate also provided high efficiency at elevated air temperatures. On the contrary, the temperature factor influenced the effectiveness of using the drug with the active substance copper oxychloride: at an increased temperature regime $\left(0.9-4.3^{\circ} \mathrm{C}\right.$ above normal), its effectiveness decreased to $85.5-90.7 \%$.

It was found that fungicides with the active ingredient copper hydroxide have a negative effect on apple plants, which is expressed in a reduction in the length of annual shoots. This action manifests itself regardless of the amount of precipitation or its absence. In addition, under conditions of elevated temperature conditions, when using the fungicide Kocide 2000, WDG, a decrease in the area of the leaf blade may occur. On the plum, the use of coppercontaining fungicides Abiga-Peak, WS and Cuproxat, SC had a negative effect on shoot growth and leaf size. The use of the preparation Terpen $\mathrm{C}, \mathrm{KS}$, containing terpene acids, stimulated the growth of one-year plum shoots by $27.7 \%$ and caused an increase in the leaf area by $11.6 \%$ in comparison with the control.

It was found that the content of copper in the fruits of apple, plum and in the soil under their plantations was in concentrations not exceeding the hygienic standards established in the Russian Federation. Thus, the use of modern copper-containing preparations does not lead to contamination of garden agrocenoses with residual amounts of gross forms of copper. 
The obtained results can be used to develop elements of energy-saving technologies for protecting apple and plum trees in a changing climate. On an apple tree, it is possible to include in the protection systems in the second half of the growing season preparations based on copper hydroxide, which provide stable, highly effective protection even under extreme weather conditions. This admit will reduce the risk of developing resistance to the scab pathogen in drugs of other chemical groups used during this period, which in practice is expressed in an increase in the intervals between treatments and, consequently, in a decrease in their number. At the plum, replacing Abiga-Peak, WS with Cuproxat, SC and Terpen C, $\mathrm{KS}$ will also reduce the number of treatments after flowering by increasing the intervals between spraying. The use of the drug Terpen $\mathrm{C}, \mathrm{KS}$ allows to reduce, in comparison with the fungicide Abiga-Peak, WS, registered for use on culture, the pesticide load on the environment due to the lower rate of copper application.

\section{References}

1. A.A. Zhuchenko, Adaptive strategy for sustainable development of agriculture in Russia in the XXI century, 1-2(816), 624 (2009)

2. I. G. Mishchenko, «Magarach». Viticulture and winemaking, 22(4), 350 (2020)

3. V.A. Khilevsky, A.A. Zverev, O.V. Kungurtseva, Bulletin of plant protection, 3(85), 50 (2015)

4. G. Yuan, AGROXXI (2018) https://www.agroxxi.ru

5. K. Weitbrecht, St. Schwab, C. Rupp, E. Bieler, M. Dürrenberger, G. Bleyer, St. Schumacher, H. Kassemeyer, R. Fuchs, Eb. Schlücker, 139, 105382 (2021)

6. S. Kuhne, D. Roßberg, P. Rőhrig, F. von Mering, F. Weihrauch, S. Kanthak, J. Kienzle, W. Patzwahl, E. Reiners, J. Gitzel, Organic Farming, 3(1), 66 (2017)

7. N.Ya. Kashirskaya, A.M. Kochkina, Achievements of science and technology of the agro-industrial complex, 33(22), 50 (2019)

8. G.V. Yakuba, Ecological protection of apple trees from scab in conditions of climatic changes, 215 (2013)

9. T.I. Yusypiva, V.S Zamorena (2011) http://www.rusnauka.com

10. V.V. Nikolenko, S.F. Kotov, Ecosystems, their optimization and protection, 2, 99 (2010) http://ekosystems.cfuv.ru

11. Q.-Y. Wang, J.-Y. Sun, X.-J. Xu, H.-W. Yu, Ecotoxicology and Environmental Safety

12. D. Fernández-Calviño, P. Soler-Rovira, Al. Polo, M. Díaz-Raviña, M. Arias-Estévez, C. Plaza, Soil Biology and Biochemistry, 42(12), 2119 (2010)

13. F. A. Sowunmi, G.T. Famuyiwa, K. A. Oluyole, S. O. Aroyeun, O. A. Obasoro, Scientific African, 6 (2019)

14. E.M. Drozdovsky, A.G. Gulyaev, A.E. Melnikov, Horticulture and viticulture, 1, 8 (1993)

15. M.E. Podgornaya, G.V. Yakuba, N.A. Kholod, S.R. Cherkezova, A.V. Vasilchenko, I.G. Mishchenko, Yu.P. Kaschits, Scientific Works of NCFSCHVW, 23, 181 (2019)

16. S.Ya. Popov, L.A. Dorozhkina, V.A. Kalinin, Fundamentals of chemical plant protection, 84 (2003)

17. B.A. Dospekhov, Field experiment technique, 352 (2014)

18. Methodological and analytical support for research in horticulture, 300 (2010)

19. Eco-friendly plant protection in vegetable growing, horticulture and viticulture (2005) 
20. V.A. Potapov, L.V. Bobrovich, N.A. Polyansky, N.V. Andreeva, Patent method for determining the area of plant leaves

21. GOST 26931-86. Methods for the determination of copper. Raw materials and food products. Methods for the determination of toxic elements, 13 (2002)

22. M-MVI-80-2008. Methods for measuring the mass fraction of elements in samples of soils, grounds and bottom sediments by atomic emission and atomic absorption spectrometry, 36 (2008) 